Western University

Scholarship@Western

Geography Publications

Geography Department

2015

\title{
Transformative Geomorphic Research Using Laboratory Experimentation
}

Sean J. Bennett

Peter Ashmore

pashmore@uwo.ca

Cheryl McKenna Neuman

Follow this and additional works at: https://ir.lib.uwo.ca/geographypub

Part of the Geography Commons

Citation of this paper:

Bennett, Sean J.; Ashmore, Peter; and Neuman, Cheryl McKenna, "Transformative Geomorphic Research Using Laboratory Experimentation" (2015). Geography Publications. 348.

https://ir.lib.uwo.ca/geographypub/348 


\section{Elsevier Editorial System(tm) for Geomorphology Manuscript Draft}

Manuscript Number:

Title: Transformative Geomorphic Research Using Laboratory Experimentation

Article Type: Special Issue: Laboratory Experiments

Keywords: experimental geomorphology, transformative research, Binghamton Geomorphology Symposium

Corresponding Author: Dr. Sean Bennett,

Corresponding Author's Institution:

First Author: Sean J Bennett

Order of Authors: Sean J Bennett; Peter Ashmore; Cheryl McKenna Neuman

Abstract: Laboratory experiments in geomorphology is the theme of the 46th annual Binghamton Geomorphology Symposium (BGS). While geomorphic research historically has been dominated by field-based endeavors, laboratory experimentation has emerged as an important methodological approach to study these phenomena, employed primarily to address issues related to scale and the analytical treatment of the geomorphic processes. It is contended here that geomorphic laboratory experiments have resulted in transformative research. Several examples drawn from the fluvial and aeolian research communities are offered as testament to this belief, and these select transformative endeavors often share very similar attributes. The 46th BGS will focus on eight broad themes within laboratory experimentation, and a strong and diverse group of scientists have been assembled to speak authoritatively on these topics, featuring several high-profile projects worldwide. This special issue of the journal Geomorphology represents a collection of the papers written in support of this symposium.

Suggested Reviewers: Pascale Biron

pascale.biron@concordia.ca

Maarten Kleinhans

M.G.Kleinhans@uu.nl

Jeff Peakall

j.peakall@leeds.ac.uk

Michael Lamb

mpl@gps.caltech.edu 
1 Transformative Geomorphic Research Using Laboratory Experimentation

2

3 Sean J. Bennett ${ }^{1}$, Peter Ashmore ${ }^{2}$, and Cheryl McKenna Neuman ${ }^{3}$

$4 \quad{ }^{1}$ Department of Geography, University at Buffalo, Buffalo, NY, USA

$5{ }^{2}$ Department of Geography, The University of Western Ontario, London, ON, CAN

$6{ }^{3}$ Department of Geography, Trent University, Peterborough, ON, CAN

7

8

9

\section{Abstract} Symposium (BGS). While geomorphic research historically has been dominated by field-based are offered as testament to this belief, and these select transformative endeavors often share very similar attributes. The $46^{\text {th }}$ BGS will focus on eight broad themes within laboratory experimentation, and a strong and diverse group of scientists have been assembled to speak authoritatively on these topics, featuring several high-profile projects worldwide. This special issue of the journal Geomorphology represents a collection of the papers written in support of this symposium.

\section{Introduction} associated landforms - has been dominated by field research endeavors. This field tradition of physiographic mapping and the necessary context to consider landscape origin and evolution (Church, 2013). The focus on field geomorphic research also is logical because geomorphologists can conduct Neuman et al., 2013). Both Butler (2013) and Harden (2013) recognize the invaluable insight and

Laboratory experiments in geomorphology is the theme of the $46^{\text {th }}$ annual Binghamton Geomorphology

endeavors, laboratory experimentation has emerged as an important methodological approach to study these phenomena, employed primarily to address issues related to scale and the analytical treatment of the geomorphic processes. It is contended here that geomorphic laboratory experiments have resulted in transformative research. Several examples drawn from the fluvial and aeolian research communities

The study of geomorphic systems - the analysis of the processes that shape the Earth's surface and their geomorphic research can be traced back to the world's early explorers, which provided the impetus for research activities at the exact locations where processes operate and landforms are created (McKenna 
broader context gained by field experiences, which potentially can lead to epiphanies in the understanding of geomorphic systems as well as serendipitous and salutary observations and discoveries simply by being in the right place at the right time.

Yet field research is not the only methodological approach available to the geomorphic research community. A second approach is numerical modeling. Here, modeling is broadly defined to include empirical and statistical approaches to quantify geomorphic phenomena, analytical approaches to define or extend governing equations, and numerical models of varying complexity to simulate geomorphic systems. At present, there is a wide array of geomorphic models available in the literature, some of which are summarized in Wilcock and Iverson (2003) and Pelletier (2008). A third methodological approach available to the geomorphic research community is physical modeling and the use of laboratory experimental facilities. Here, physical modeling is broadly defined to include scaled models based on similarity principles, analogue models based on similarity in form and/or composition,

42 and single-purpose facilities designed to explore a specific geomorphic phenomenon. Experimental 43 investigation has been part of geomorphology for many decades although there are few treatises or 44 seminal papers reporting on the design and use of laboratory experiments and facilities in geomorphology. Some representative examples include Hjulström and Sundborg (1962), Mosely and Zimpfer (1978), Schumm et al. (1987, and references therein), Peakall et al. (1996), Paola et al. (2009),

47 and McKenna Neuman et al. (2013).

The annual Binghamton Geomorphology Symposium (BGS) is one of the most recognizable geoscience 50 meetings worldwide. For nearly 50 years, the symposium series has addressed a wide range of scientific 51 and socially-relevant topics in geomorphology, engaging a multitude of geoscientists (Sawyer et al., 52 2014). The continued success of the symposium is due, in part, to the dedication and commitment of 
the BGS Steering Committee comprised of both long-term and rotating members. These individuals

54 work closely with the geomorphology community to identify emerging topics of scientific importance,

55 they facilitate greatly in the organization and success of each symposium, and they ensure that the

56 products for the symposium are disseminated to the global community in a timely fashion. The titles of

57 previous symposia illustrate the timeliness and relevance of the selected topic (Sawyer et al., 2014). But

58 the BGS has not yet organized a formal discussion of laboratory experiments in geomorphology, one of

59 the methodological approaches embraced by the research community. The $46^{\text {th }}$ Binghamton

60 Geomorphology Symposium, entitled "Laboratory Experiments in Geomorphology," seeks to bring

61 together leading experts and emerging scientists actively engaged in experimental geomorphic research.

62 This special issue introduces those invited papers to be presented the symposium. The objectives of

63 this paper are as follows: (1) to define the motivations of the geomorphic laboratory experimentalist, (2)

64 to illustrate through select case studies the transformative nature of geomorphic experimental research,

65 and (3) to provide the rationale for the $46^{\text {th }}$ BGS on laboratory experiments in geomorphology. It is

66 contended here that geomorphic research has been greatly enhanced and transformed by laboratory

67 experiments, and the future of geomorphic research depends on the continued successful melding of

68 the three approaches to geomorphic research: field work, numerical modeling, and laboratory

69 experimentation.

70

71 Motivations of the Geomorphic Laboratory Experimentalist

72 There may be several ways to define the term experimental geomorphology. Mosley and Zimpfer

73 (1978) stated that it is the study of a physical representation or model of a selected geomorphic feature

74 under laboratory conditions. Schumm et al. (1987) provided a brief historical context for experimental

75 geomorphology, including some very early case studies.

76 
There are several advantages afforded the geomorphic laboratory experimentalist, but the motivations

78 to employ such facilities, and to invest so heavily into methods, procedures, and infrastructure, can be

79 reduced to two issues: scale and prediction. The temporal and spatial scales over which geomorphic

80 processes operate often are very large. In general, spatial scales for geomorphic systems can span from

$8110^{-8}$ to $10^{7} \mathrm{~km}^{2}$, and the time scales of persistence can span from $10^{2}$ to $10^{9} \mathrm{yr}$ (Bloom, 1998). Although

82 technological advances and numerical models have facilitated the study of such systems in the field

83 (Church, 2013), these large time and space scales potentially could pose insurmountable challenges to

84 the geomorphologist. Consequently, geomorphologists have employed experimental facilities and

85 physical analogues to compress time and shrink scale, while exerting experimental control, to examine

86 the dynamics of these systems. In general, laboratory experiments have spatial scales that range from

$8710^{-2}$ to $10^{2} \mathrm{~m}^{2}$ (or $10^{-8}$ to $10^{-4} \mathrm{~km}^{2}$ ), and time scales of persistence for such processes that range from $10^{0}$

88 to $10^{6} \mathrm{~s}$ (or $10^{-7}$ to $10^{-2} \mathrm{yr}$ ), or potentially even shorter in length (ms).

This large discrepancy in scale between natural geomorphic systems and many laboratory facilities

91 remains the primary challenge to the experimentalist. Dimensional analysis and the use of similarity

92 principles have long been employed successfully in the design and execution of laboratory experiments

93 and their application to natural settings (Yalin, 1971; Peakall et al., 1996; Julien, 2002; Gallisdorfer et al.,

94 2014). Unfortunately, application of similarity principles to experimental apparatuses typically

95 employed for geomorphic research invariably requires some relaxation of these scaling requirements, as

96 well as some distortion of select ratios and dimensions. In general, distortions often are accepted for

97 the depth of the geophysical flow and the size and density of the sediment on the boundary or in

98 transport. Paola et al. (2009) further loosened these rigorous requirements by arguing that even poorly-

99 scaled experiments seem to capture the primary characteristics of the geomorphic system under

100 investigation, presenting several examples in support of this belief. They employed the phrase 
101 "unreasonable effectiveness" to refer to the consistency of observations made between these poorly-

102 scaled experimental systems and their field prototypes. Even with much analytical evidence presented

103 and the "unreasonable effectiveness" of experimental systems, skeptism remains within the broader

104 geomorphic community when laboratory experiments of geomorphic systems are compared to their

105 natural analogues (Paola et al., 2009).

106

107 The second motivation for the geomorphic experimentalist is the focus on prediction. As noted by Paola

108 et al. (2009), geomorphologists are moving away from reasoning by analogy toward reasoning by

109 analysis. It is often difficult to describe in analytic terms the equations governing geomorphic processes

110 due to the large number of degrees of freedom that can occur in natural settings. This is particularly

111 challenging in field-based research where temporal and spatial scales are large or where the processes

112 themselves may not be observed or measured directly. It is this quest to define these fundamental

113 relationships and their governing equations that drives the geomorphologist into the laboratory.

114 Through controlled experimentation, functional relationships and robust theory for geomorphic

115 phenomena emerge, so that these analytic arguments then can be tested against both experimental and

116 field data and further refined (see also Schumm et al., 1987; Paola et al., 2009). It is this iterative

117 process between reasoning (see Kleinhans et al., 2010), experimentation, and field application that leads

118 to generalized theory, geomorphic transport laws, and predictive explanations of landforms (Dietrich et

119 al., 2003).

120

121 There are additional benefits afforded to the geomorphic experimentalist. Experimental

122 geomorphologists seek control, precision, and reproducibility in their work (Mosley and Zimpfer, 1978;

123 Paola et al., 2009; McKenna Neuman et al., 2013). Control is derived from knowing exactly when and

124 where a geomorphic event or process will occur so that all data collection activities can be planned in 
advance. Precision is derived from the use of technology and appurtenant devices that measure with

126 great resolution and accuracy all parameters deemed important. Experimental uncertainties in

127 measured parameters rarely exceed a few percent, even though the phenomenon under investigation

128 can be highly dynamic. Reproducibility is derived from knowing that the experiments can be executed

129 again and again, either by the initial scientist or by others, and that the results will (or should) be

130 statistically invariant. Such opportunities for comprehensive study of geomorphic phenomena often are

131 rarely possible in field research (Schumm et al., 1987; Paola et al., 2009). For these reasons,

132 experimental geomorphologists also are expected to be meticulous scientists.

133

134 Major disadvantages to geomorphic experimental research, however, also have been identified. These 135 disadvantages include (1) problems with the boundary conditions of the physical model, (2) materials 136 used and processes observed in laboratory experiments may be dissimilar when compared to those in 137 nature, and (3) the study of a restricted number of processes or phenomena may mask more complex 138 interactions observed in nature (Mosley and Zimpfer, 1978). Experimental geomorphologists likely are 139 well aware of such potential problems.

140

\section{Select Examples of Transformative Experimental Geomorphic Research}

142 A common phrase used in academia today is transformative research. A definition for transformative 143 research can be found in a report prepared by National Science Foundation (NSF, 2007):

Transformative research is defined as research driven by ideas that have the potential to radically change our understanding of an important existing scientific or engineering concept or leading to the creation of a new paradigm or field of science or engineering. Such 

new frontiers (p. 10).

151 While this definition appears to be self-explanatory, identifying examples of transformative

152 experimental geomorphic research remains highly subjective. Below a few examples are provided of 153 studies that are considered to be transformative, with the knowledge that these examples represent the 154 obvious bias of the authors and that many more examples could have been presented.

Rill networks and landscape evolution

157 In the late 1960s, faculty in the Civil Engineering Department at Colorado State University created a 158 research initiative to investigate the hydrology of small watersheds (Dickinson et al., 1967). A specific 159 research focus was the creation of an experimental research facility to examine watershed response to 160 rainfall. The primary objective for this facility was quite modest: it should be large enough to respond as 161 a prototype watershed, but small enough to permit controlled variation of watershed and rainfall 162 characteristics. The outdoor facility built was a rectangular box $9.1 \mathrm{~m}$ wide, $15.2 \mathrm{~m}$ long, and $1.8 \mathrm{~m}$ 163 deep, and it was fitted with upward-directed vertical sprinklers that could simulate rainfall at up to four 164 intensities.

Shortly after its construction, Parker (1977) used this facility to examine the evolution of drainage basins

167 and the growth and development of rill networks. To do this, he filled the basin with a sandy loam 168 sediment mixture, fashioned the topography into an initially flat, gently sloping surface, and then 169 subjected the system to continuous rainfall and episodic baselevel lowering. Although Parker (1977) 170 reported on only two experiments, these results were very enlightening. Parker documented the time171 and space-evolution of rill networks forced by rainfall and baselevel lowering, and he could link network 
172 extension and sediment efflux to each wave of degradation imposed on the system. Parker then used

173 these data to assess current models of network initiation, extension, and abstraction, to document the 174 role of knickpoints in communicating exogenically-forced perturbations through the network, and to 175 address sediment budgets, sediment delivery ratios, and sequestration of sediments along evolving 176 channel networks. The results from this experimental campaign can be found in Parker (1977), Parker 177 and Schumm (1982), and most prominently in Schumm et al. (1987).

179 This experimental work is considered transformative for two reasons. First, Parker (1977) and his 180 advisor, Stanley Schumm, noted that due to the short time available to the geomorphologist, theories 181 and models of landscape evolution depended quite heavily on inferences based on limited field data.

182 Moreover, they also noted that simulation models for hillslope and landscape evolution available during 183 this time period made a number of simplifying assumptions, and they could not necessarily be tested 184 against empirical data. As such, Parker and Schumm recognized that experimentation could be used to 185 fill this obvious gap between field observations and numerical and simulation models, and it could 186 provide the necessary empirical data to test hypotheses and to explore parameter space.

187 Geomorphologists now routinely conduct experimental campaigns in direct support of analytic and 188 numerical models (e.g., Hancock and Willgoose, 2001; Paola et al., 2009). Second, while Parker and 189 Schumm (1982; Schumm et al., 1987) focused their attention on landscape evolution, the experimental 190 facility they employed also could be used to address hillslope processes directly responsible for soil 191 degradation, which was especially important to soil scientists, agricultural engineers, and the farming 192 community. Thus, the same facility and experimental methods could be used by a wide range of 193 researchers straddling different disciplines and having different perspectives and complementary 194 objectives, yet servicing completely different clientele. Many examples now exist of using similar 
apparatuses with different disciplinary foci (Brunton and Bryan, 2000; Pelletier, 2003; Rieke-Zapp and

196 Nearing, 2005; Douglass and Schmeeckle, 2007; Gordon et al., 2012).

Flow and sediment transport in sand-bedded channels

199 The most notable flume experiments ever conducted on sediment transport were those summarized by

200 Gilbert (1914). Gilbert, a charter member of the U.S. Geological Survey (USGS) began this work a few

201 years earlier while stationed in California. He observed that some rivers, including the Sacramento

202 River, were experiencing overloading of sediment (aggradation) due to the waste from hydraulic mines.

203 Gilbert sought to study bedload transport, and how the quantity of load was related to river channel 204 slope and flow.

205

206 To this end, Gilbert (1914) and his colleagues constructed a flume at the University of California-

207 Berkeley. The flume was $9.6 \mathrm{~m}$ long, $0.60 \mathrm{~m}$ wide, and 0.30 to $0.55 \mathrm{~m}$ deep, it could recirculate water, 208 and sediment could be fed into the flow at the upstream end (see Parker and Wilcock, 1993). For a 209 given flow rate, Gilbert and his colleagues would feed different sediment mixtures (unisize and mixed210 size sand and fine gravel) into the flume at various rates using a wide range of flow discharges. A 211 number of important observations and results were reported in this work, which included the following:

212 (1) empirical formulae for the prediction of bedload transport, (2) the various modes of bedload

213 transport, (3) the formation and movement of dunes, the transition of dunes to upper-stage plane beds,

214 and the transition of upper-stage plane beds to upstream migrating antidunes, and (4) the enhanced 215 mobility of coarser-grained sediment in the presence of finer-grained sediment.

217 The work of Gilbert (1914) is transformative for a number of reasons. First, it is one of the first empirical 218 studies of flow and sediment transport using an experimental channel. Second, the data collected are 
still being used today, primarily to test and verify bedload transport equations (e.g., Wiberg and Smith, 1989; Bridge and Bennett, 1992). Third, Gilbert and his USGS and university colleagues used experimental facilities to address a societal problem. Gilbert's work is considered to be highly influential

222 for these reasons, being cited more than 750 times using Harzing's Publish or Perish citation search tool.

In September of 1956, several decades after Gilbert's (1914) work, the Water Resources Division of the general, and flow resistance and sediment transport rates, in particular (Guy et al., 1966). Luna Leopold was the Chief Hydrologist at that time, and his own research on river dynamics, water and land conservation, and floods embodied this new initiative. Given the large quantity of data required to address this problem, it was decided by Leopold and his colleagues that recirculating flumes would be employed since these were comparable to flow and sediment processes observed in most streams of interest (Guy et al., 1966).

The primary outcome of this project was the publication of a U.S. Geological Survey Professional Paper by Guy et al. (1966), which was a compilation of 339 experiments conducted over a period of five years and employing a number of graduate students and agency personnel. In this report, two tilting

236 recirculating flumes (one was $2.44 \mathrm{~m}$ wide, $0.61 \mathrm{~m}$ deep, and $45.72 \mathrm{~m}$ long, the other was $0.61 \mathrm{~m}$ wide, $2370.76 \mathrm{~m}$ deep, and $18.29 \mathrm{~m}$ long; both located at Colorado State University) were filled with 10 different sands (median sizes ranging from very fine to coarse sand) and systematically subjected to a wide range

239 of flow conditions (Froude numbers Fr ranging from 0.14 to 1.70 , where $F r=u / \sqrt{g d}$, $u$ is mean downstream flow velocity, $g$ is gravitational acceleration, and $d$ is mean flow depth). The data collected

241 in these experiments was exhaustive, and included water surface slope, mean flow depth and rate, 242 vertical profiles of downstream flow velocity and suspended sediment concentration, bedload transport 
rate, and bed configuration. Interestingly, the report provides little to no analysis, discussion, or

244 interpretation of the data.

245

246 The experimental techniques employed and the empirical data presented would appear pedestrian by

247 modern standards, yet the publication by Guy et al. (1966) is considered transformative for the following

248 reasons. First, its premise was based on a recognized scientific and societal need-improving the

249 current understanding of mass transport and floods in rivers and streams, and that a federal agency

250 would assume the responsibility to do this. Second, it represented the first systematic data collection

251 program of flow and sediment transport processes in sand-bedded channels. As such, the data collected

252 and the observations made would become the foundations for nearly all theories related to bedform

253 stability and transition, sediment transport, analysis of fine-scale sedimentary deposits, and hydraulic

254 resistance in rivers (e.g., Rubin and Hunter, 1982; van Rijn, 1984; Southard, 1991; Bridge and Bennett,

255 1992; Leclair and Bridge, 2001) as well as other geophysical flows of interest (e.g., Miller and Komar,

256 1980; Mulder and Alexander, 2001). Third, this work forged a new paradigm in experimental research,

257 one that was focused on instrumentation and infrastructure (Williams, 1971). It is no surprise that Guy

258 et al. (1966) has been highly cited (>525 times using Harzing's Publish or Perish citation search tool).

Birth of aeolian geomorphology

261 Wind erosion processes are notoriously difficult to study in the field. Unlike rivers, for example, which

262 represent confined flows that are unidirectional and more or less continuous through time, boundary

263 layer flows in the atmosphere are unconfined, omni-directional, ephemeral, and extend over entire

264 regions. Aeolian transport is initiated at wind speeds that often are an order of magnitude greater than

265 in water, so that the ensuing particle motion is not only rapid but also short-lived during wind gusts.

266 Aeolian geomorphologists are well acquainted with the disappointment of spending many days to weeks 
267 in the field waiting for suitable winds to trigger a transport event, only to have their instruments set up

268 in the 'wrong' location and/or orientation relative to the prevailing conditions. Early seminal work in the 269 1930s through the 1950s, which laid the foundation for studying the physics of particle transport by

270 wind in laboratory and portable wind tunnels, was borne out of both curiosity and crisis, and perhaps

271 also, a good deal of frustration. The convenience of being able to create a unidirectional airflow at the

272 desired wind speed whenever required provided early engineers and soil scientists with an invaluable

273 tool and transformative insights that amounted to the birth of aeolian 'process' geomorphology.

274

275 Without question the founder of modern aeolian geomorphology was Brigadier Ralph A. Bagnold, a

276 pioneer of desert exploration, who as an engineer and first commander of the British Army's Long Range

277 Desert Group made the earliest recorded crossing of the Libyan Desert (Bagnold, 1990). Upon his

278 subsequent retirement from the army in 1935, Bagnold constructed the first wind tunnel designed for

279 the sole purpose of studying the inception and transport of sedimentary particles in airflows. Housed in

280 the hydraulics laboratory at Imperial College, University of London, the plywood tunnel had an open-

281 loop, suction-type configuration with a small cross-section $(0.3 \mathrm{~m} \times 0.3 \mathrm{~m})$ but a comparatively long

282 fetch $(9 \mathrm{~m})$. Laboratory wind tunnels must be highly customized for studying particle motion, and

283 indeed it is an art that depends strongly on the experience of the researcher and the resources

284 available. Even to this day, particles are generally not permitted in wind tunnel facilities used for

285 research on the physics of fluids, owing to problems with sediment abrasion and recirculation. Bagnold

286 borrowed heavily from his engineering studies in fluid dynamics, however, to adapt instruments for

287 obtaining measurements in particle-laden flows.

289 In 1941, Bagnold published a seminal book entitled "The Physics of Blown Sand and Desert Dunes" in 290 which he summarizes, compares and integrates findings from his laboratory experiments with 
observations made in the field. To this day, this monograph remains the most frequently cited work in

292 aeolian geomorphology (>4000 citations using Harzing's Publish or Perish). Bagnold's accomplishments

293 include describing and quantifying the inception of motion and transport of particles in atmospheric

294 boundary layer flows, identifying saltation (sand particles moving in a ballistic trajectory) as the primary

295 mode of aeolian transport, and distinguishing between the impact and fluid thresholds for particle

296 entrainment. Bagnold attempted, for the first time, to understand and describe the linkages between

297 the physics of the transport phenomena and aeolian bedform development (e.g., ripples and dunes).

298 Although many of his perceptions concerning such linkages have been superseded and refined with

299 ongoing technological developments (as reviewed by Shao, 2010), the core concepts, terminologies, and

300 methodologies introduced by Bagnold (1941) remain soundly imprinted upon present-day aeolian

301 geomorphology. His laboratory experiments and theoretical developments were transformative in that

302 they provided a new foundation to build upon, one based on the laws of physics and engineering

303 practice, as opposed to earlier subjective approaches involving qualitative description and classification.

304 In subsequent initiatives, Bagnold expanded his experimental interests to the physics of sediment

305 transport by water in alluvial channels (see Bagnold, 1966), participating in flume experiments with

306 Leopold of the USGS (see above) and his co-workers.

Responding to the Dust Bowl Era

309 The largest environmental disaster to affect North America was the drought and associated wind

310 erosion that occurred in the 1930s, a period known as the Great Dust Bowl. In response to the

311 devastation, amounting to an estimated loss of 480 tons of soil per acre by 1938 (Hansen and Libecap,

312 2004), the High Plains Wind Erosion Laboratory of the U.S. Department of Agriculture (later named the

313 Wind Erosion Research Unit or WERU) was established in 1947 on the campus of Kansas State

314 Agricultural College in Manhattan, KS. William S. Chepil joined the unit in 1948 and beginning in 1953, 
315 led it for a decade. Chepil was widely recognized as a pioneer of wind erosion research in North

316 America, a career that was launched from his doctoral thesis research at the University of Minnesota

317 (Chepil, 1940) and his early work as a soil scientist with the Canada Department of Agriculture. The

318 WERU 'laboratory' hosted a large collection of custom designed research equipment, inclusive of several

319 wind tunnels of varied scale and configuration. A particularly novel initiative was the deployment of a

320 portable field wind tunnel that could be placed over undisturbed natural surfaces of wide-ranging

321 texture and roughness.

322

323 Similar to Bagnold, Chepil carried out basic research into the dynamics of soil erosion by wind (e.g.,

324 Chepil, 1945a, b, c), but in accordance with the mission-driven nature of WERU, emphasis was placed

325 upon examining the key factors governing wind erosion, and upon developing methods to reduce or

326 eliminate soil loss by wind (e.g., Chepil and Woodruff, 1963). The overarching goal was to develop a

327 Wind Erosion Equation (WEQ) that would parallel the Universal Soil Loss Equation (USLE) used for

328 predicting water erosion. The transformative work carried out under Chepil's direction substantially

329 extended the highly idealized experimental conditions (e.g. dry quartz particles) examined by Bagnold,

330 and firmly established the role of both laboratory and portable field wind tunnels in the development

331 and validation of semi-empirical predictive models describing the erosion of natural soils by wind. On

332 the whole, the large body of journal publications produced by the unit (over 50 by Chepil alone)

333 provided the seminal foundation for understanding the effects of soil texture, structure, and

334 aggregation, surface roughness, and cohesion (e.g., water and organic matter content) in aeolian

335 systems. This work also established a number of measurement techniques that are still used to quantify

336 these governing factors.

337

338

Morphology of alluvial channels 
For over a century, many concepts and insights about fluvial landforms, processes, and responses have

340 been derived from laboratory experiments and models (e.g., Schumm et al., 1987) based in

341 experimental programs established in laboratories around the world. In many cases the laboratory work

342 contains essential insights, tests, and measurements that are not possible from field observations and

343 also provide ideas that can be transferred to analysis of problems in the field or provide some

344 verification of inferences from field observations. One thinks, for example, of Friedkin's (1945)

345 descriptions of meander morphology and dynamics, which has many successors (and some

346 predecessors), or the observations of Leopold and Wolman (1957) of the formation of braids under

347 equilibrium conditions, which contained the essential insight that braiding is an equilibrium state that

348 "does not necessarily indicate excess of total load" and which is the antecedent of several experimental 349 programs on morphology and bedload in braiding rivers in particular (Schumm et al., 1987; Warburton, 350 1996). In this sense, the development of experimental programs in fluvial geomorphology is

351 transformative as a whole, bringing both exploratory and formal experimental (including theory testing) 352 and predictive-analytical programs to the discipline.

Experimentation on cross-section morphology and dimensions has been prominent in establishing principles, observations, and predictive relations for this fundamental aspect of fluvial systems. Leopold et al. (1960) and Wolman and Brush (1961) used experiments to derive insights into the determination

357 of flow resistance from irregular channel boundaries, the factors controlling river channel dimensions, 358 and application of channel mechanics for fluvial morphology. This complemented the early hydraulic 359 geometry and regime analyses from field data and provided experimental observations and formal tests 360 of theory to stimulate and support these analyses, helping to establishing formal analytical and experimental work as an essential part of geomorphology. 
The focus on channel morphology and pattern motivated another study important to the geomorphic

364 community. The Hydraulics Research Station, Wallingford, UK, was established in the early 1950s partly

365 to study 'loose boundary' problems primarily for civil engineering. The experimental work of Ackers

366 (1964) is an early example of the use of small-scale rivers to generate new observations and

367 measurements of morphological characteristics and processes of development, and also to explicitly

368 derive and test empirical and theoretical relations for predicting, in this case, alluvial channel

369 dimensions and compare results with full-scale channels. His experiments used a simple sand box about

$370100 \mathrm{~m}$ long and $30 \mathrm{~m}$ wide divided into $10 \mathrm{~m}$ wide strips each with a different grade of sand. Initial

371 conditions were straight channels with trapezoidal cross-section and erodible boundary and channel

372 development was observed until a stable state (no measurable change over extended period of time)

373 was reached at constant (channel-forming) discharge. Sediment flux was determined by the conditions

374 in the channel by using a sediment recirculation system to give conditions equivalent to an infinitely

375 long channel. Channels were 1 to $3 \mathrm{~m}$ wide and up to $0.2 \mathrm{~m}$ deep with discharges up to $30 \mathrm{I} / \mathrm{s}$.

376 Adjustment to a stable state included a tendency to meander in some cases. In part, the study was

377 aimed at comparing predictions from physical theory derived from fundamental equations of river

378 mechanics with empirical formulae developed in the regime approach.

The results of the experiments of Ackers (1964) showed that empirical relations for dimensions of small

381 channels were consistent with physical theory. They also established the hydraulic basis for the

382 importance of width-depth ratio in channel mechanics and its relation to differences in bed and bank

383 material, consistent with the contemporary field observations of Schumm (1960). The analysis also

384 established the possibility of a regime sediment concentration. The rational formulations gave

385 reasonable agreement with the experimental results, showed the crucial role of bedform resistance in

386 channel morphology, and established the principle that both a resistance law and a transport law were 
essential for rational prediction of channel dimensions (consistent also with Henderson, 1961). The

388 experiments also helped to establish connections between river engineering and geomorphology, which

389 have proved extremely fruitful in fluvial geomorphology. The debate about empirical versus 'rational'

390 formulae for predicting and explaining river channel dimensions has been a central concern in fluvial

391 geomorphology ever since and continues to some extent today (Eaton, 2013). Ackers' (1964) work was

392 followed by similar experiments on meander geometry (Ackers and Charlton, 1970). Experimental work

393 on river channel geometry has become almost commonplace since the 1960 s, both in single and multi-

394 thread channels both for empirical investigation and explicit theory testing (e.g., Warburton et al., 1996;

395 Eaton and Church, 2007).

\section{Bar development in alluvial channels}

398 Experimental observations of bar development in rivers have provided crucial insights into the 399 formation, morphology, and dynamics of these features, stimulating theoretical developments and 400 insights applicable to field conditions in which observations are much more difficult to make, initial 401 conditions unknown, and fundamental relations may be obscured by local contingencies. Insights into 402 the role of bars in development of river channel patterns, and associated theoretical explanations, come 403 primarily from experimental studies that can be traced back to several laboratories in Japan where river 404 morphology and engineering were prominent issues in landscape processes and society. Rooted in the 405 observations from rivers, these experimental studies were intended to reproduce the morphological 406 characteristics of a variety of rivers and analyze the conditions controlling the occurrence of particular 407 morphologies. Studies of this type began in the 1950s (e.g., Kinoshita, 1957) based on principles of 408 morphological similarity in small-scale rivers. Many subsequent analyses of alternate bars and more 409 complex bar patterns in rivers can be traced back to this initial work, and the resulting data from experiments such as Ikeda $(1973,1975)$ are still used in tests of theoretical models of bar morphology 
411 and dimensions. As a group, these studies used experimental flumes in several laboratories with a

412 variety of dimensions and sediment types, which could be manipulated to set up a range of initial

413 conditions (e.g. channel width/depth ratio, gradient, flow depth) to run experiments covering the known

414 range of relevant parameters.

415

416 These flume experiments establishing a simple typology of bars have become the foundation for many

417 aspects of fluvial morphodynamics (Dietrich, 1987; Yalin and da Silva, 2001). The results of these early

418 experiments, and subsequent work (e.g., Ikeda, 1984; Fujita, 1989) defined the conditions of sediment

419 mobility and channel cross-section shape under which each bar pattern (and related river morphology)

420 occurred and the conditions for transition between types. The controlling variables (excess shear

421 velocity and the product of slope and width-depth ratio) were established from dimensional analysis of

422 the problem and then subjected to experimental tests. This demonstrated how experimental work both

423 benefitted from and was used to stimulate theoretical analysis, as well as yielding fundamental

424 observations and demonstrating the application of dimensional analysis (derived mainly from

425 developments in river engineering) to problems and experimental modeling of river geomorphology.

426 The flume results were directly related to observations of channel morphology and pattern in reaches of

427 the Omoi River with differing morphology, and other rivers in Japan, demonstrating the applicability of

428 the experimentally-derived predictions of morphological transitions and differences to real rivers (Ikeda,

429 1975). The variables identified by Ikeda (1973) from dimensional analysis and experiments were, in

430 part, also the variables derived from mathematical stability theories for explaining bar modes and

431 channel pattern formation (e.g., Parker, 1976). The distinction between single row and multiple row

432 bars described by Ikeda (1973) has become a fundamental element of fluvial morphodynamics in

433 relation to channel pattern development (e.g., Ferguson, 1987; Bridge, 1993). Experimentation 
434 continues to be used in refining these relations, testing theory, and validating numerical models of bar 435 morphology and dynamics (e.g., Lanzoni, 2000; Jang and Shimizu, 2005).

438 The previous section provided several examples of experimental geomorphic research deemed by the 439 authors as transformative. This list is not exhaustive, it is decidedly biased, and it is restricted in time 440 during a period where the financial support for engineering and science was different. Nevertheless, 441 several commonalities amongst these studies do emerge, suggesting that these attributes may have 442 played a role in producing research having high and long-lasting impact. These attributes are listed 443 below.

1. Visionary leadership. It is not surprising that several transformative research efforts were initiated or supervised by now-recognized leaders within the geomorphic community. Each of these individuals was broadly trained and brought a strong affinity for field research into the laboratory.

2. Scientific and/or societal need. In each example presented above, the trigger to begin the endeavor is the same: a real or perceived scientific and/or society need to conduct the research. Moreover, none of the efforts could be considered incremental, as per the definition by NSF (2007).

3. Involvement of a federal agency or institution. It is remarkable that several examples had a federal agency or research institution serving as the primary entity conducting the work, with some cooperating directly with universities. This suggests that appropriated (potentially non- 
success of the research program. Interestingly, this research transpired unencumbered by competitive funding agencies and the professional expectations of academia.

4. New or repurposed facilities. As expected, new or repurposed experimental facilities,

\section{Rationale for and Composition of the $46^{\text {th }}$ Binghamton Geomorphology Symposium}

468 There are three primary drivers for hosting a symposium entitled "Laboratory Experiments in

469 Geomorphology," and two already have been noted. First, no BGS symposium has focused on the topic

470 of laboratory experiments, in spite of enormous activity in this area. Second, few treatises currently are

471 available to the geomorphic community that provide detailed information about the design,

472 construction, and execution of laboratory experiments, and how these facilities can used for

473 transformative research. Third, the importance of experimental facilities in research on Earth surface

474 processes was recently highlighted by the National Research Council (2010). This report noted that

475 experimental research can be used to develop, test, and validate geomorphic transport laws as well as

476 examine the emergence of organized landscapes. The report also noted the rebirth in the use of

477 relatively large experimental facilities such as St. Anthony Falls Laboratory's Outdoor StreamLab,

478 University of Minnesota, and the Landscape Evolution Observatory research facility at Biosphere2,

479 University of Arizona, both of which will be featured in the symposium. These relatively large facilities 
create or even necessitate interdisciplinary research opportunities, they can represent more realistic

481 biotic processes, and they can reduce or even eliminate many issues related to scale.

482

There are many geomorphic themes that can be examined through experimentation. Owing to the

484 short duration of the symposium, and to the single-session venue, the co-organizers identified eight (8)

485 topics that could be represented at the symposium, which span a wide range of environments and

486 scales. These topics are as follows: (1) granular flows and hillslopes, (2) fluvial processes, (3) aeolian

487 processes, (4) coastal and marine processes, (5) glacial and periglacial geomorphology, (6) landscape and

488 planetary processes, (7) biophysical and ecogeomorphic processes, and (8) large-scale facility

489 development and data management. This is not an exclusive inventory, but it helped to frame the list of

490 potential contributors.

491

492 Using these themes, the co-organizers assembled a long list of potential speakers, which was then

493 whittled down in size. To accomplish this, the co-organizers were motivated to achieve strong diversity

494 within the program on the basis of gender, geography, career stage, and perspective. Table 1 is the final

495 list of those scientists invited to the symposium. In every case, the co-organizers were able to secure

496 commitments from the top candidates in each thematic area. Several high-profile facilities and projects

497 also are represented here including the National Center for Earth Surface Dynamics 2 (University of

498 Minnesota), St. Anthony Falls Laboratory's Outdoor StreamLab (University of Minnesota), the USGS

499 Cascade Volcano Observatory Debris-Flow Flume (Washington), the Landscape Evolution Observatory

500 research facility at Biosphere2 (University of Arizona), the Total Environment Simulator (University of

501 Hull), and the EarthCube and the Sediment Experimentalist Network (among others).

502

503

504 
Table 1: Summary of BGS themes, invitees (alphabetical) and institutions, and topic areas.

\begin{tabular}{|c|c|c|}
\hline Name & Institution & Topic \\
\hline \multicolumn{3}{|c|}{ Granular Flows and Hillslope Processes } \\
\hline David J. Furbish & Vanderbilt University & Hillslope processes \\
\hline Gerard Govers & Katholieke Universiteit & Rill erosion \\
\hline Richard M. Iverson & USGS Cascades Volcano Observatory & Debris flows \\
\hline \multicolumn{3}{|l|}{ Fluvial Processes } \\
\hline Maarten G. Kleinhans & Universiteit Utrecht & River and delta morphodynamics \\
\hline Michael P. Lamb & California Institute of Technology & Steep river channels \\
\hline Chris Paola & University of Minnesota & Clastic depositional systems \\
\hline Elowyn M. Yager & University of Idaho & Coarse sediment transport \\
\hline \multicolumn{3}{|l|}{ Aeolian Processes } \\
\hline$\overline{\text { Keld R. Rasmussen }}$ & University of Aarhus & Wind tunnel simulation of planetary surfaces \\
\hline \multicolumn{3}{|c|}{ Coastal and Marine Processes } \\
\hline Heidi Nepf & Massachusetts Institute of Technology & Flow-sediment-vegetation interactions \\
\hline Jeff Peakall & University of Leeds & Submarine channels \\
\hline \multicolumn{3}{|l|}{ Glacial Processes } \\
\hline Neal R. Iverson & lowa State University & Laboratory experiments of glacial processes \\
\hline \multicolumn{3}{|c|}{ Landscape and Planetary Processes } \\
\hline Lucy E. Clarke & University of Gloucestershire & Alluvial fans \\
\hline Fabien Graveleau & Université des Sciences et Technologies de Lille & Landform evolution \\
\hline \multicolumn{3}{|c|}{ Biophysical and Ecogeomorphic Processes } \\
\hline Anne F. Lightbody & University of New Hampshire & Biological boundary layers \\
\hline Joanna C. Curran & Northwest Hydraulic Consultants & River restoration \\
\hline \multicolumn{3}{|c|}{ Large-scale Facility Development and Data Management } \\
\hline Leslie Hsu & Lamont-Doherty Earth Observatory & Data sharing \\
\hline Stuart J. McLelland & University of Hull & Total Environment Simulator \\
\hline Peter A. Troch & University of Arizona & Landscape Evolution Observatory, Biosphere2 \\
\hline
\end{tabular}

507 The primary outlet for disseminating the results of the symposium is publication of peer-reviewed

508 papers prepared by the invitees in a special issue of the journal Geomorphology. Authors were given

509 freedom to explore these topics, and to include any co-authors, as they saw fit. The papers contained

510 within this special issue are those submitted in support of the $46^{\text {th }}$ BGS.

\section{Conclusions}

513 Geomorphology is a discipline that historically has been dominated by field-based research endeavors.

514 Yet both numerical modeling and laboratory experimentation offer unrivalled methodological

515 opportunities for the geoscience community. The Binghamton Geomorphology Symposium (BGS) is a 
516 highly visible annual meeting that has addressed a wide range of scientifically important and socially

517 relevant topics in geomorphology. The $46^{\text {th }}$ annual BGS will focus on the topic of laboratory

518 experiments.

519

520 The two primary motivations of the experimentalist are to address the scale of geomorphic systems and

521 to predict such phenomena in analytic terms. First, geomorphic processes often operate at relatively

522 large time and space scales, which pose significant challenges to the field scientist. Laboratory

523 experiments can effectively compress time and shrink scale, and there exists ample evidence to suggest

524 that experimental results can be applied to field prototypes. Second, geomorphologists now seek to

525 explain Earth surface processes and landform development in analytic terms. Laboratory

526 experimentation can greatly facilitate the development and testing of generalized theory, which then

527 can be applied to field observations.

528

529 It is contended here that laboratory experimentation of geomorphic systems has resulted in

530 transformative research. Several examples, primarily from fluvial and aeolian research, are presented in

531 support of this claim, and included the following: (1) rill networks and landscape evolution in soils, (2)

532 flow and sediment transport in sand-bedded recirculating flumes, (3) wind erosion research, and (4) bar

533 development and river channel pattern. These transformative research endeavors often were driven by

534 visionary leaders in federal agencies or institutions where specialized experimental facilities were

535 created or repurposed. Moreover, the research featured in these examples effectively straddled the

536 disciplines of engineering and geoscience.

537

538 Laboratory experimentation of geomorphic systems is the focus the $46^{\text {th }}$ Binghamton Geomorphology

539 Symposium. Eight themes within geomorphology were selected as foci for the meeting. The symposium 
shall feature a strong and diverse assemblage of scientists with a wide range of perspectives, and it will

report on several high-profile facilities and projects. This special issue of the journal Geomorphology

presents as a group those papers submitted in support of this symposium.

543

544

545

546

547

548

549

550

551

552

553

554

555

556

557

558

559

560

561

562

563

564

565

566

567

568

569

570

571

572

573

574

575

576

577

578

579

580

581

582

583

584

\section{References}

Ackers, P., 1964. Experiments on small streams in alluvium. Journal of the Hydraulics Division, American Society of Civil Engineers, 90 (HY4), 1-37.

Ackers, P., Charlton, F.G., 1970. The geometry of small meandering streams. Proceedings of the Institution of Civil Engineers, Paper 7328, 289-317.

Bagnold, R.A., 1941. The Physics of Blown Sand and Desert Dunes. Methuen, London, 265 pp.

Bagnold, R.A., 1966. An approach to the sediment transport problem from general physics. United States Department of the Interior, U.S. Geological Survey, Professional Paper 0422-I, Government Printing Office, Washington, D.C., $37 \mathrm{pp}$.

Bagnold, R.A., 1990. Sand, Wind, and War: Memoirs of a Desert Explorer. Tucson, University of Arizona Press, $209 \mathrm{pp}$.

Bloom, A.L., 1998. Geomorphology: A Systematic Analysis of Late Cenozoic Landforms. Prentice Hall, Upper Saddle River, 482 pp.

Bridge, J.S., 1993. The interaction between channel geometry, water flow, sediment transport and deposition in braided rivers. In: Best, J.B., Bristow, C.S. (Eds.), Braided Rivers. Special Publication 75, Geological Society Publishing House, Bath, pp. 13-71.

Bridge, J.S., Bennett, S.J., 1992. A model for the entrainment and transport of sediment grains of mixed sizes, shapes, and densities. Water Resources Research 28, 337-363.

Brunton, D.A., Bryan, R.B., 2000. Rill network development and sediment budgets. Earth Surface Processes and Landforms 25, 783-800.

Butler, D.R., 2013. The field tradition in mountain geomorphology. Geomorphology 200, 42-49.

Chepil, W.S., 1940. The relation of wind erosion to some physical soil characteristics. Doctoral thesis, University of Minnesota, Minneapolis, $65 \mathrm{pp}$.

Chepil, W.S.. 1945a. Dynamics of wind erosion. I. Nature of movement of soil by wind. Soil Science 60(4), 305-320.

Chepil, W.S.. 1945b. Dynamics of wind erosion. II. Initiation of soil movement. Soil Science 60(4), 397411.

Chepil, W.S., 1945c. Dynamics of wind erosion. III. The transport capacity of the wind. Soil Science 60(6), 475-480.

Chepil, W.S., Woodruff, N.P. 1963. The physics of wind erosion and its control. Advances in Agronomy 15, 211-302.

Church, M., 2013. Refocusing geomorphology: Field work in four acts. Geomorphology 200, 184-192.

Dickinson, W.T., Holland, M.E., Smith, G.L., 1967. An experimental rainfall-runoff facility. Hydrology Paper No. 25, Colo. State Univ., Ft. Collins, 81 pp.

Dietrich, W.E., 1987. Flow and sediment transport in river bends. In: Richards, K. (Ed.), River Channels: Environment and Process. The Institute of British Geographers, Blackwell, Oxford, pp. 179-227.

Dietrich, W.E., Bellugi, D.G., Sklar, L.S., Stock, J.D., Heimsath, A.M., Roering, J.J., 2003. Geomorphic transport laws for predicting landscape form and dynamics. In: Wilcock, P.R., Iverson, R.M. (Eds.), Prediction in Geomorphology. American Geophysical Union, Washington, DC, pp. 103-132.

Douglass, J., Schmeeckle, M., 2007. Analogue modeling of transverse drainage mechanisms. Geomorphology 84, 22-43. 
Eaton, B.C., 2013. Hydraulic geometry: empirical investigations and theoretical approaches. In: Shroder, J. (Editor in Chief), Wohl, E. (Ed.), Treatise on Geomorphology. Academic Press, San Diego, vol.9, Fluvial Geomorphology, 314-329.

Eaton B.C., Church M., 2007. Predicting downstream hydraulic geometry: A test of rational regime theory. Journal of Geophysical Research-Earth Surface, 112(F03025): doi: 10.1029/2006JF000734.

Ferguson, R.I., 1987. Hydraulic and sedimentary controls of channel pattern. In: Richards, K. (Ed.), River Channels: Environment and Process. The Institute of British Geographers, Blackwell, Oxford, pp. 129-158.

Friedkin, J.F., 1945. A laboratory study of the meandering of alluvial rivers. U.S. Waterways Experiment Station, Vicksburg, Mississippi, 40 pp.

Fujita, Y., 1989. Bar and channel formation in braided streams. In: Ikeda, S., Parker, G. (Eds.), River Meandering. American Geophysical Union Water Resources Monograph 12, Washington D.C., pp. 417-462.

Gallisdorfer, M.S., Bennett, S.J., Atkinson, J.F., Ghaneeizad, S.M., Brooks, A.P., Simon, A., Langendoen, E.J., 2014. Physical-scale model designs for engineered log jams in rivers. Journal of Hydroenvironment Research 8, 115-128.

Gilbert, G.K., 1914. The transportation of debris by running water. U.S. Geological Survey Professional Paper 86, Government Printing Office, Washington, D.C., 263 pp.

Gordon, L.M., Bennett, S.J., Wells, R.R., 2012. Response of a soil-mantled experimental landscape to exogenic forcing. Water Resources Research 48, W10514, doi:10.1029/2012WR012283.

Guy, H.P., Simons, D.B., Richardson, E.V., 1966. Summary of alluvial channel data from flume experiments, 1956-61. U.S. Geological Survey Professional Paper 462-I, U.S. Govt. Printing Office, Washington, DC, $96 \mathrm{pp}$.

Hancock, G., Willgoose, G., 2001. Use of a landscape simulator in the validation of the SIBERIA catchment evolution model: Declining equilibrium landforms. Water Resources Research 37, 19811992.

Hansen, Z.K., Libecap, G.D., 2004. Small farms, externalities, and the Dust Bowl of the 1930s. Journal of Political Economy 112(3), 665-694.

Harden, C., 2013. Geomorphology in context: Dispatches from the field. Geomorphology 200, 34-41.

Henderson, F.M., 1961. Stability of alluvial channels. Journal of the Hydraulics Division, American Society of Civil Engineers 87(HY6), 109-138.

Hjulström, F., Sundborg, A., 1962. The Geomorphological Laboratory. Acta Universitatis upsaliensis, Ser. A, No 176, 27-41.

Ikeda, H., 1973. A study of the formation of sand bars in an experimental flume. Geographical Review of Japan 46-7, 435-452.

Ikeda, H., 1975. On the bed configuration in alluvial channels: their types and condition of formation with reference to bars. Geographical Review of Japan 48-10, 712-730.

Ikeda, S., 1984. Prediction of alternate bar wavelength and height. Journal of Hydraulic Engineering 110, 371-386.

Jang, C.-L., Shimizu, Y., 2005. Numerical simulation of relatively wide, shallow channels with erodible banks. Journal of Hydraulic Engineering 131, 565-575.

Julien, P.Y., 2002. River Mechanics. Cambridge University Press, New York, 434 pp.

Kinoshita, R., 1957. Formation of dunes on river beds-an observation of the condition of river meandering. Proceedings of the Japanese Society of Civil Engineers 42, 1-21.

Kleinhans, M.G., Bierkens, M.F.P., van der Perk, M., 2010. On the use of laboratory experimentation: "Hydrologists, bring out shovels and garden hoses and hit the dirt." Hydrology and Earth System Sciences 14, 369-382. 
Lanzoni, S., 2000. Experiments on bar formation in a straight flume 2. Graded sediment. Water Resources Research 36, 3351-3363.

Leclair, S.F., Bridge, J.S., 2001. Quantitative interpretation of sedimentary structures formed by river dunes. Journal of Sedimentary Research 71, 713-716.

Leopold, L.B., Bagnold, R.A., Wolman, M.G., Brush, L.M., 1960. Flow resistance in sinuous or irregular channels. U.S. Geological Survey Professional Paper 282-D, U.S. Govt. Printing Office, Washington, D.C., 111-134.

Leopold, L.B., Wolman, M.G., 1957. River channel patterns: braided, meandering and straight. U.S. Geological Survey Professional Paper 282-B, U.S. Govt. Printing Office, Washington, D.C., 39-85.

McKenna Neuman, C., Ashmore, P., Bennett, S.J., 2013. Laboratory and experimental geomorphology: Examples from fluvial and aeolian systems. In: Shroder, J. (Editor in Chief), Orme, A.R., Sack, D. (Eds.), Treatise on Geomorphology. Academic Press, San Diego, vol. 1, The Foundations of Geomorphology, pp. 325-348.

Miller, M.C., Komar, P.D., 1980. Oscillation sand ripples generated by laboratory apparatus. Journal of Sedimentary Petrology 50, 173-182.

Mosley, M.P., Zimpfer, G.L., 1978. Hardware models in geomorphology. Progress in Physical Geography 2, 438-461.

Mulder, T., Alexander, J., 2001. The physical character of subaqueous sedimentary density flows and their deposits. Sedimentology 48, 269-299.

National Research Council, 2010. Landscapes on the Edge: New Horizons for Research on Earth's Surface. Committee on Challenges and Opportunities in Earth Surface Resources, Board on Earth Sciences and Resources, Division on Earth and Life Studies, The National Academies Press, Washington, D.C., 180 pp.

National Science Foundation, 2007. Enhancing support of transformative research at the National Science Foundation. National Science Board NSB-07-32, 13 pp. (available at http://www.nsf.gov/nsb/documents/2007/tr_report.pdf).

Paola, C., Straub, K., Mohrig, D., Reinhardt, L., 2009. The "unreasonable effectiveness" of stratigraphic and geomorphic experiments. Earth Science Reviews 97, 1-43.

Parker, G., 1976. On the cause and characteristic scales of meandering and braiding in rivers. Journal of Fluid Mechanics 76, 457-480.

Parker, G., Wilcock, P., 1993. Sediment feed and recirculating flumes-fundamental difference. Journal of Hydraulic Engineering 119, 1193-1204.

Parker, R.S., 1977. Experimental study of basin evolution and its hydrologic implications. Hydrology Paper No. 90, Colo. State Univ., Ft. Collins, 58 pp.

Parker, R.S., Schumm, S.A., 1982. Experimental study of drainage networks. In: Bryan, R., Yair, A. (Eds.), Badland Geomorphology and Piping, Geo Books, Norwich, 153-168.

Peakall, J., Ashworth, P., Best, J., 1996. Physical modelling in fluvial geomorphology: Principles, applications and unresolved issues. In: Rhoads, B.L., Thorn, C.E. (Eds.), The Scientific Nature of Geomorphology. John Wiley \& Sons, Chichester, pp. 221-253.

Pelletier, J.D., 2003. Drainage basin evolution in the Rainfall Erosion Facility: dependence on initial conditions. Geomorphology 53, 183-196.

Pelletier, J.D., 2008. Quantitative Modeling of Earth Surface Processes. Cambridge University Press, New York, $304 \mathrm{pp}$.

Rieke-Zapp, D.H., Nearing, M.A., 2005. Slope shape effects on erosion: A laboratory study. Soil Science Society of America Journal 69, 1463-1471.

Rubin, D.M., Hunter, R.E., 1982. Bedform climbing in theory and nature. Sedimentology 29, 121-138.

Sawyer, C.F., Butler, D.R., O'Rourke, T., 2014. An historical look at the Binghamton Geomorphology Symposium. Geomorphology 223, 1-9. 
Schumm, S.A., 1960. The shape of alluvial channels in relation to sediment type. U.S. Geological Survey Professional Paper 352-B, U.S. Govt. Printing Office, Washington, D.C., 17-30.

Schumm, S.A., Mosley, M.P., Weaver, W.E., 1987. Experimental Fluvial Geomorphology. John Wiley, New York, $413 \mathrm{pp}$.

Shao, Y., 2010. Physics and Modelling of Wind Erosion. Lexington, Springer, $452 \mathrm{pp.}$

Southard, J.B., 1991. Experimental determination of bed-form stability. Annual Review of Earth and Planetary Science 19, 423-55.

van Rijn, L.C., 1984. Sediment transport, Part III: Bed forms and alluvial roughness. Journal of Hydraulic Engineering 110, 1733-1754.

Warburton, J., 1996. Hydraulic modelling of braided gravel-bed rivers. Journal of Hydrology (New Zealand) 35, 153-156.

Wiberg, P.L., Smith, J.D., 1989. Model for calculating bed load transport of sediment. Journal of Hydraulic Engineering 115, 101-123.

Wilcock, P.R., Iverson, R.M. (Eds.), 2003. Prediction in Geomorphology. Geophysical Monograph Series, Vol. 135, American Geophysical Union, Washington DC, 256 pp.

Williams, G.P., 1971. Aids in designing laboratory flumes. U.S. Geological Survey Open-File Report 71327. Government Printing Office, Washington, D.C., 294 pp.

Wolman M.G., Brush, L.B., 1961. Factors controlling the size and shape of stream channels in coarse noncohesive sands: a laboratory study of the development of equilibrium channels. U.S. Geological Survey Professional Paper 282-G, U.S. Govt. Printing Office, Washington, D.C., 183-210.

Yalin, M.S., 1971. Theory of Hydraulic Models. Macmillan, London, 266 pp.

Yalin, M.S., da Silva, A.M.F., 2001. Fluvial Processes. International Association of Hydraulic Engineering and Research, Delft, The Netherlands, $197 \mathrm{pp}$. 